\title{
HUBUNGAN KEBIASAAN CUCI TANGAN PAKAI SABUN DENGAN KEJADIAN INFEKSI KECACINGAN PADA ANAK SEKOLAH DASAR (STUDI LITERATUR) Wahyuni Sahani ${ }^{1}$, Oktovina Sanda Limbong ${ }^{2}$ \\ 1,2 Jurusan Kesehatan Lingkungan Poltekkes Kemenkes Makassar *)wahyuni sahani@yahoo.com
}

\begin{abstract}
In developing countries like Indonesia, there are still many diseases that become health problems, one of which is helminthiasis. It is estimated that more than $60 \%$ of children in Indonesia suffer from worm infection, low-quality sanitation is the cause. The purpose of this study was to determine the relationship between handwashing habits with soap before eating, after defecation (BAB), and after playing with the incidence of helminthiasis in elementary school children. This type of research is a literature study. The 6 journals from 2016 - 2019, at Dukuh Kupang V Surabaya Elementary School, in school children in the Coastal Area of Tadui Village, Mamuju District, at Taqwiyatul Wathon Islamic Elementary School, North Semarang, in State Elementary School No. 5 Delod Peken Tabanan, at the State Elementary School in the Rumbai Coastal District of Pekanbaru and SDN Inpres No. 1 Wora, Wera District, Bima Regency. The results found there is a relationship between handwashing habits with the incidence of helminthiasis with Sig. $=0.012, P$-value $=0.02$ and $P$-value $=0.04, P$ value $=0.018, P$-value $=0.001, P$-value $=0.001$, and $P$-value $=0.00$. As for who was stated to have a significant relationship with the incidence of intestinal worms is the habit of washing hands with soap before eating, the habit of washing hands with soap after bowel movements, the habit of washing hands with soap after playing. The conclusion of this study is there is a relationship between handwashing habits with soap before eating, after defecation, and after playing with the incidence of helminthiasis in elementary school children.
\end{abstract}

Keywords : Wash hands with soap, worms

\section{ABSTRAK}

Di negara yang sedang berkembang seperti Indonesia, masih banyak penyakit yang menjadi masalah kesehatan, salah satunya adalah infeksi kecacingan. Diperkirakan lebih dari $60 \%$ anak-anak di Indonesia menderita suatu infeksi cacing, rendahnya mutu sanitasi menjadi penyebabnya.Tujuan penelitian ini adalah untuk mengetahui hubungan kebiasaan cuci tangan pakai sabun sebelum makan, sesudah buang air besar (BAB), dan setelah bermain dengan kejadian infeksi kecacingan pada anak sekolah dasar. Jenis penelitian yang digunakan adalah studi literatur. Adapun 6 jurnal dari tahun 2016 - 2019, pada SDN Dukuh Kupang V Surabaya, pada anak sekolah di Daerah Pesisir Desa Tadui Kecamatan Mamuju, pada SD Islam Taqwiyatul Wathon, Semarang Utara, pada Sekolah Dasar Negeri No. 5 Delod Peken Tabanan, pada Sekolah Dasar Negeri Kecamatan Rumbai Pesisir Pekanbaru dan SDN Inpres No. 1 Wora Kecamatan Wera Kabupaten Bima.Hasil penelitian ditemukan ada hubungan kebiasaan cuci tangan dengan kejadian infeksi kecacingan dengan nilai Sig. $=0,012, P$-value $=0.02$ dan $P$-value $=0.04, P$-value $=0,018, P$-value $=0,001, P$-value $=0,001$, dan $P$-value $=0,00$. Adapun yang dinyatakan memiliki hubungan bermakna dengan kejadian kecacingan ialah kebiasaan cuci tangan pakai sabun sebelum makan, kebiasaan cuci tangan pakai sabun sesudah BAB, kebiasaan cuci tangan pakai sabun sesudah bermain.Kesimpulan dari penelitian ini adalah ada hubungan kebiasaan cuci tangan pakai sabun sebelum makan, setelah BAB dan setelah bermain dengan kejadian infeksi kecacingan pada anak sekolah dasar.

Kata Kunci : Cuci tangan pakai sabun, Kecacingan

\section{PENDAHULUAN}

Di negara yang sedang berkembang seperti Indonesia, masih banyak penyakit yang menjadi masalah kesehatan, salah satunya adalah infeksi kecacingan yang ditularkan melalui tanah atau dikenal dengan Soil Transmitted Helminths (STH). Infeksi kecacingan ini sering dijumpai pada anak usia sekolah dasar di mana pada usia ini anak masih sering kontak dengan tanah.

Berdasarkan data dari World Health Organization (WHO) pada tahun 2015 (Magee et al., 2017) menyebutkan bahwa lebih dari 1,5 miliar orang atau $24 \%$ dari populasi dunia terinfeksi oleh Soil Transmitted Helminth (STH). $\mathrm{Di}$ Indonesia pun prevalensi penyakit kecacingan masih tinggi, yaitu 45-65\%. Di wilayah-wilayah tertentu dengan sanitasi yang buruk, prevalensi kecacingan dapat mencapai
$80 \%$ (Chadijah, Sumolang, \& Veridiana, 2014). Berdasarkan hasil penelitian faktor yang berhubungan dengan kejadian kecacingan pada siswa SDN Inpres 1 Wora Kecamatan Wera Kabupaten Bima juga ditemukan prevalensi kecacingan 59,3 \%. Prevalensi Ascaris lumbricoides 55,6 \%. Distribusi kelompok umur 6-8 Tahun 52,7 \%, dan distribusi jenis kelamin perempuan 50,5\%, distribusi kondisi jamban baik 59,3\%, ketersediaan air bersih baik 79,1\%, kebiasaan mencuci tangan tidak baik $73,6 \%$, dan kebersihan kuku tidak baik 58,2\% (Syahrir \& Aswadi, 2016)

Data UNICEF pada tahun 2014 mengungkapkan bahwa $75,5 \%$ masyarakat Indonesia tidak mencuci tangan karena menganggap tangan mereka bersih. Padahal, salah satu cara paling murah untuk mencegah 
Jurnal Sulolipu : Media Komunikasi Sivitas Akademika dan Masyarakat

Vol. 20 No.22020

e-issn : 2622-6960, p-issn : 0854-624X

kematian dan penyakit yang berhubungan dengan diare adalah cuci tangan dengan sabun. Menurut data WHO (2014), mencuci tangan dengan sabun dapat mengurangi $40 \%$ resiko diare dan $20 \%$ resiko infeksi saluran pernapasan akut, termasuk pneumonia. (Triwijanarko, Ramadhan. 2017).

Data dari Dinas Kesehatan Kota Makassar pada tahun 2017 juga menyebutkan bahwa jumlah kasus kecacingan sebanyak 1928 dan pada tahun 2018 jumlah kasus kecacingan sebanyak 1747. Pada Puskesmas Toddopuli diperoleh data pada tahun 2017 sebanyak 24 kasus kecacingan, kemudian untuk kasus kecacingan yang terjadi dan pada tahun 2018 sebanyak 68 kasus kecacingan (Dinkes Kota Makassar, 2019).

\section{METODE \\ Desain penelitian}

Jenis penelitian yang digunakan adalah studi literatur. Studi literatur merupakan pengumpulan data dan informasi dengan cara menggali pengetahuan atau ilmu dari sumbersumber seperti buku, karya tulis, diktat catatan kuliah, serta beberapa sumber lainnya yang ada hubungannya dengan objek penelitian seperti diutarakan oleh Dewi (2017) yang meneliti tahun 2014

\section{Variabel penelitian}

1. Cuci tangan pakai sabun sebelum makan

2. Cuci tangan pakai sabun setelah $B A B$

3. Cuci tangan pakai sabun setelah bermain

4. Kejadian Infeksi kecacingan

\section{Pengumpulan Data}

Pengumpulan data bersumber dari data primer dan data sekunder yaitu data yang di ambil dari pustaka, jurnal-jurnal dan data dari Dinas Kesehatan Kota Makassar.

\section{Pengolahan dan Analisis Data}

Pengolahan data dilakukan dengan mengumpulkan data, setelah data terkumpul dilakukan editing kemudian dimasukan kedalam tabel kemudian dilengkapi dengan narasi. Analisis data dengan dengan membaca dan menganalisa jurnal-jurnal penelitian sebelumnya yang telah ada untuk melihat adanya hubungan kebiasaan cuci tangan pakai sabun dengan kejadian infeksi kecacingan.

HASIL

Penelitian studi literatur tentang hubungan kebiasaan mencuci tangan pakai sabun dengan kejadian infeksi kecacingan pada anak sekolah dasar dilaksanakan pada bulan Maret sampai bulan Mei 2020. Adapun sumber referensi yang diperoleh dari hasil penelitian sebelumnya yang dilaksanakan oleh beberapa peneliti sebelumnya dimana terdapat 6 hasil penelitian yang akan dipaparkan dan disajikan sebagai berikut :

\begin{tabular}{|c|c|c|c|c|}
\hline \multirow{2}{*}{$\begin{array}{l}\text { Kebiasaan } \\
\text { cuci } \\
\text { tangan }\end{array}$} & $\begin{array}{l}\text { Infeksi } \\
\text { usus }\end{array}$ & cacing & Total & \multirow[t]{2}{*}{$\begin{array}{l}\text { Spearman } \\
\text { test }\end{array}$} \\
\hline & Tidak & $\overline{Y a}$ & & \\
\hline Ya & $\begin{array}{l}13 \\
(92 \\
9 \%)\end{array}$ & $\begin{array}{l}1(7, \\
1 \%)\end{array}$ & $\begin{array}{l}14 \\
(100 \%)\end{array}$ & \multirow[t]{3}{*}{$\begin{array}{l}\text { Value } \\
0,433 \\
\text { Sig. = } 0,012\end{array}$} \\
\hline Tidak & $\begin{array}{l}10 \\
(52, \\
6 \%)\end{array}$ & $\begin{array}{l}9 \\
(47,4 \\
\%)\end{array}$ & $\begin{array}{l}19 \\
(100 \%)\end{array}$ & \\
\hline Total & $\begin{array}{l}23 \\
(69 \\
7 \%)\end{array}$ & $\begin{array}{l}10 \\
(30,3 \\
\%)\end{array}$ & $\begin{array}{l}33 \\
(100 \%)\end{array}$ & \\
\hline
\end{tabular}

Sumber : Data primer (Putra, 2019)

Berdasarkan hasil uji Spearman test diperoleh nilai Sig. $=0,012(<0,05)$, artinya ada hubungan kebiasaan cuci tangan dengan angka kejadian infeksi cacing usus pada siswa SDN Dukuh Kupang 5 Surabaya.

Tabel 2 Kebiasaan Mencuci Tangan Pada Anak Sekolah Dengan Kejadian Kecacingan Di Daerah Pesisir Desa Tadui Kecamatan Mamuju Tahun 2016

\begin{tabular}{|c|c|c|c|c|c|c|c|}
\hline \multirow{3}{*}{ Variabel } & \multicolumn{4}{|c|}{ Infeksi Cacing } & \multirow{2}{*}{\multicolumn{2}{|c|}{ Total }} & \multirow{3}{*}{$\begin{array}{l}P \\
\text { Value }\end{array}$} \\
\hline & \multicolumn{2}{|c|}{ Positif } & \multicolumn{2}{|c|}{ Negatif } & & & \\
\hline & $\mathrm{N}$ & $\%$ & $\mathrm{~N}$ & $\%$ & $\mathrm{n}$ & $\%$ & \\
\hline \multicolumn{8}{|c|}{ Kebiasaan Mencuci tangan Sebelum Makan } \\
\hline $\begin{array}{l}\text { Tidak } \\
\text { mencuci } \\
\text { tangan }\end{array}$ & 32 & 64,0 & 18 & 36,0 & 50 & 54,9 & \multirow[t]{2}{*}{0,02} \\
\hline $\begin{array}{l}\text { Mencuci } \\
\text { tangan }\end{array}$ & 35 & 85,4 & 6 & 14,6 & 41 & 45,1 & \\
\hline
\end{tabular}

Sumber : Data primer (Saeni \& Arief, 2016)

Nilai $p$ value antara kebiasaan mencuci tangan sebelum makan dengan kejadian kecacingan sebesar 0.02, berdasarkan Uji Chi-Square diperoleh $p<0,05$ berarti ada hubungan diantara kebiasaan mencuci tangan sebelum makan dengan kejadian infeksi kecacingan. Adapun $\mathrm{p}$ value antara kebiasaan mencuci 
Jurnal Sulolipu : Media Komunikasi Sivitas Akademika dan Masyarakat

Vol. 20 No.22020

e-issn : 2622-6960, p-issn : 0854-624X

tangan setealah BAB dengan kejadian kecacingan adalah 0.04 , berdasarkan Uji ChiSquare apabila diperoleh $p<0,05$ berarti ada hubungan antara kebiasaan mencuci tangan sesudah BAB dengan kejadian infeksi kecacingan.

Tabel 3 Infeksi Cacing Usus Soil Transmitted Helminths Terhadap Kebiasaan Mencuci Tangan pada Siswa SD Tahun 2018

\begin{tabular}{|c|c|c|c|c|c|c|c|}
\hline \multirow{3}{*}{$\begin{array}{l}\text { Kebiasaa } \\
\mathrm{n} \\
\text { mencuci } \\
\text { tangan }\end{array}$} & \multicolumn{4}{|c|}{ Kecacingan } & \multirow{2}{*}{\multicolumn{2}{|c|}{ Total }} & \\
\hline & \multicolumn{2}{|c|}{ Positif } & \multicolumn{2}{|c|}{ Negatif } & & & \\
\hline & $\mathrm{N}$ & $\%$ & $\mathrm{~N}$ & $\%$ & $\mathrm{~N}$ & $\%$ & \\
\hline Buruk & 5 & $\begin{array}{l}5,4 \\
3\end{array}$ & $\begin{array}{l}2 \\
1\end{array}$ & $\begin{array}{l}22,8 \\
2\end{array}$ & $\begin{array}{l}2 \\
6\end{array}$ & $\begin{array}{l}28,2 \\
6\end{array}$ & $\begin{array}{l}\text { Valu } \\
e\end{array}$ \\
\hline Baik & 2 & $\begin{array}{l}2,1 \\
7\end{array}$ & $\begin{array}{l}6 \\
4\end{array}$ & $\begin{array}{l}69,5 \\
6\end{array}$ & $\begin{array}{l}6 \\
6\end{array}$ & $\begin{array}{l}71,7 \\
4\end{array}$ & 0,018 \\
\hline Total & 7 & 7,6 & $\begin{array}{l}8 \\
5\end{array}$ & $\begin{array}{l}92,3 \\
8\end{array}$ & $\begin{array}{l}9 \\
2\end{array}$ & 100 & \\
\hline
\end{tabular}

Sumber : Data primer (Tifannov, 2018)

Hasil analisis dengan menggunakan uji chisquare test di peroleh nilai $p$-value sebesar 0,018 , dapat disimpulkan terdapat hubungan yang bermakna antara kebiasaan mencuci tangan dengan infeksi kecacingan.

Tabel 4 Hubungan Perilaku Higienitas Diri Dan Sanitasi Sekolah Dengan Infeksi Soil Transmitted Helminths Pada Siswa Kelas III-VI Sekolah Dasar Negeri No. 5 Delod Peken Tabanan Tahun 2017

\begin{tabular}{|c|c|c|c|c|c|c|c|}
\hline \multirow{3}{*}{$\begin{array}{c}\text { Aktifitas } \\
\text { mencuci } \\
\text { tangan }\end{array}$} & \multicolumn{4}{|c|}{ Infeksi cacing } & \multirow{2}{*}{\multicolumn{2}{|c|}{ Total }} & \multirow{4}{*}{$\begin{array}{c}P \\
\text { Value } \\
0,001\end{array}$} \\
\hline & \multicolumn{2}{|c|}{ Positif } & \multicolumn{2}{|c|}{ Negatif } & & & \\
\hline & $\mathrm{N}$ & $(\%)$ & $\mathrm{N}$ & $(\%)$ & $\mathrm{N}$ & (\%) & \\
\hline Baik & 1 & 1,25 & 79 & 98,75 & 80 & 100 & \\
\hline Buruk & 7 & 28 & 18 & 72 & 25 & 100 & \\
\hline
\end{tabular}

Sumber : Data primer (Dewi N, 2017)

Adapun nilai $P$-value $=0,001$, berdasarkan $U j \mathrm{ji}$ Chi-Square apabila diperoleh $p<0,05$ berarti ada hubungan antara kebiasaan mencuci tangan dengan infeksi kecacingan pada anak.

Tabel 5 Kejadian Kecacingan pada Siswa Sekolah Dasar Negeri Kecamatan Rumbai Pesisir Pekanbaru Tahun 2016

\begin{tabular}{|c|c|c|c|c|c|c|}
\hline \multirow[b]{2}{*}{$\begin{array}{c}\text { Kebiasaa } \\
\text { n mencuci } \\
\text { tangan }\end{array}$} & \multicolumn{2}{|c|}{ Infeksi cacing } & \multicolumn{2}{|c|}{ Jumlah } & \multirow[b]{2}{*}{$\begin{array}{c}P \\
\text { value }\end{array}$} & \multirow[b]{2}{*}{$\begin{array}{c}\text { POR } \\
(95 \% \\
\mathrm{Cl})\end{array}$} \\
\hline & $\begin{array}{c}\mathrm{Ya} \\
\mathrm{n} \\
(\%)\end{array}$ & $\begin{array}{c}\text { Tidak } \\
N \\
(\%)\end{array}$ & $\bar{N}$ & $(\%)$ & & \\
\hline Tidak & $\begin{array}{l}30 \\
(31,3\end{array}$ & $\begin{array}{l}66 \\
(68,8 \\
)\end{array}$ & 96 & $\begin{array}{l}10 \\
0\end{array}$ & $\begin{array}{l}0,00 \\
1\end{array}$ & $\begin{array}{l}6,818 \\
(3,061 \\
-\end{array}$ \\
\hline Ya & $\begin{array}{l}9 \\
(63)\end{array}$ & $\begin{array}{l}35 \\
(93,8\end{array}$ & $\begin{array}{l}14 \\
4\end{array}$ & $\begin{array}{l}10 \\
0\end{array}$ & & $\begin{array}{l}15,189 \\
)^{159}\end{array}$ \\
\hline
\end{tabular}

Sumber : Data primer (Kartini, 2016)
Hasil uji bivariat terhadap pada variabel kebiasaan mencuci tangan mempunyai hubungan signifikan dengan kejadian infeksi cacing yaitu kebiasaan mencuci tangan dengan nilai $\mathrm{p}$-value $=0,001$. Karena hasil Uji ChiSquare diperoleh $p<0,05$ berarti ada hubungan yang bermakna antara kebiasaan cuci tangan dengan kejadian infeksi cacing.

Tabel 6 Faktor Yang Berhubungan Dengan Kejadian Kecacingan Pada Siswa SDN Inpres No. 1 Wora Kecamatan Wera Kabupaten Bima Tahun 2016

\begin{tabular}{|c|c|c|c|c|c|c|c|}
\hline \multirow{3}{*}{$\begin{array}{c}\text { Kebiasaan } \\
\text { Mencuci } \\
\text { tangan }\end{array}$} & \multicolumn{4}{|c|}{ Kejadian Kecacingan } & \multirow{2}{*}{\multicolumn{2}{|c|}{ Total }} & \multirow{6}{*}{$\begin{array}{c}P \\
(0,00)\end{array}$} \\
\hline & & sitif & $\mathrm{Ne}$ & & & & \\
\hline & $\mathrm{n}$ & $(\%)$ & $n$ & $(\%)$ & $\mathrm{n}$ & $(\%)$ & \\
\hline Baik & 3 & 12,5 & 21 & 87,5 & 24 & 100 & \\
\hline Tidak baik & 51 & 76,1 & 16 & 23,9 & 67 & 100 & \\
\hline Total & 54 & 59, & 37 & 40,7 & 91 & 100 & \\
\hline
\end{tabular}

Sumber : Data primer (Syahrir \& Aswadi, 2016)

Adapun hasil uji Chi-Square diperoleh nilai $P=$ 0,00. Berdasarkan Uji Chi-Square apabila diperoleh $p<0,05$ berarti ada hubungan antara kebiasaan mencuci tangan dengan kejadian cacingan.

\section{PEMBAHASAN}

Hubungan Cuci Tangan Pakai Sabun Sebelum Makan Dengan Kejadian Infeksi Kecacingan

Pada penelitian (Putra, 2019) yang dilakukan di SD Daerah Pesisir Desa Tadui Kecamatan Mamuju tahun 2019 pada 33 orang anak yang menjadi sampel penelitian. Penelitian tersebut menguji hubungan kebiasaan mencuci tangan sebelum makan dengan kejadian infeksi cacing pada anak. Desain penelitiannya adalah cross sectional. Hasil yang ditemukan adalah bahwa adanya kebiasaan mencuci tangan sebelum makan dengan kejadian infeksi cacing pada anak (value $=0,433$ ). Pada penelitian ini dinyatakan terinfeksi cacing ada sebanyak 10 siswa. Adapun siswa yang memiliki kebiasaan tidak cuci tangan ada 9 siswa yang dinyatakan positif terinfeksi cacing, sedangkan untuk yang miliki kebiasaan cuci tangan ada 1 siswa yang dinyatakan positif terinfeksi cacing. Siswa yang memiliki kebiasaan tidak mencuci tangan selesai bermain berpotensi lebih besar terinfeksi cacing daripada siswa yang memiliki kebiasaan mencuci tangan. 
Jurnal Sulolipu : Media Komunikasi Sivitas Akademika dan Masyarakat

Vol. 20 No.22020

e-issn : 2622-6960, p-issn : 0854-624X

Infeksi yang terjadi pada siswa di SDN 5 Kupang Surabaya berasal dari aktivitas bermain yang melakukan kontak dengan tanah diluar lingkungan sekolah yang tidak diimbangi dengan mencuci tangan. Anak-anak sekolah biasanya langsung makan makanan mereka tanpa cuci tangan terlebih dahulu padahal sebelumnya mereka telah bermain-main. Adapun sumber infeksi dapat berasal dari tanah atau air yang terkontaminasi, makanan yang mengandung stadium infektif, yaitu stadium parasit yang dapat menginfeksi manusia (Natadisastra \& Agoes, 2009). Berdasarkan observasi yang dilakukan peneliti mengenai kondisi lingkungan yang kumuh, kurangnya pengetahuan tentang PHBS, kurangnya jamban sehat, serta kurangnya tempat cuci tangan umum terutama di daerah sekitar sekolah juga memperbesar kemungkinan anak terkena infeksi kecacingan.

Pada penenelitian (Saeni \& Arief, 2016) yang dilakukan di Daerah Pesisir Desa Tadui Kecamatan Mamuju pada 91 anak sekolah yang menjadi sampel. Penelitian tersebut menguji hubungan kebiasaan mencuci tangan pada anak sekolah dengan kejadian kecacingan. Desain penelitiannya adalah cross sectional. Hasil yang ditemukan adalah ada hubungan diantara kebiasaan mencuci tangan sebelum makan dengan kejadian infeksi kecacingan dengan nilai $p$-value $=0.02$. Pada penelitian ini dinyatakan positif terinfeksi cacing sebanyak 67 siswa. Adapun siswa yang memiliki kebiasaan tidak mencuci tangan sebelum makan ada 32 siswa yang dinyatakan positif terinfeksi cacing, sedangkan siswa yang memiliki kebiasaan mencuci tangan sebelum makan ada 35 siswa yang dinyatakan positif terinfeksi cacing. Pada penelitian ini kita dapat melihat bahwa meski anak memiliki kebiasaan mencuci tangan sebelum makan juga masih berpotensi mengalami kecacingan itu disebabkan karena ada faktor lain yang menyebabkan seorang anak mengalami kecacingan seperti kebiasaan mandi dan kebersihan kuku pada anak.

Tangan merupakan bagian tubuh kita yang paling banyak tercemar kotoran dan bibit penyakit. Ketika memegang sesuatu, dan berjabat tangan, tentu ada bibit penyakit yang menempel pada kulit tangan kita. Setelah kita memegang pintu kamar kecil (sumber penyakit yang berasal dari tinja manusia), saat mengeringkan tangan dengan lap di dapur, memegang uang, lewat pegangan kursi di kendaraan umum atau bagian-bagian tempat umum yang bisa disentuh oleh siapapun, tangan hampir pasti tercemar bibit penyakit jenis apa saja. Kebiasaan mencuci tangan dengan sabun sebelum makan adalah bagian dari perilaku hidup bersih dan sehat, untuk mencegah suatu penyakit masuk kedalam tubuh seseorang. Faktor yang dapat menyebabkan tingginya prevalensi infeksi cacing adalah rendahnya tingkat perilaku hidup bersih dan sehat (Munir, White, \& Ramadani, 2019).

Untuk mencegah terjadinya infeksi kecacingan pada anak ialah dengan memutus rantai penularan infeksi kecacingan yang ditularkan melalui tangan antara lain dengan menjaga kebersihan diri misalnya mencuci tangan sebelum makan dengan sabun di air mengalir. Dimana salah satu waktu penting perlunya cuci tangan pakai sabun yang dinyatakan dalam Permenkes ialah sebelum makan (Republik Indonesia, 2014). Adapun pengendalian untuk infeksi kecacingan yang bisa dilakukan ialah dengan memberi anak obat cacing setiap 6 bulan sekali.

\section{Hubungan Cuci Tangan Pakai Sabun Sesudah Buang Air Besar (BAB) Dengan Kejadian Infeksi Kecacingan}

Pada penenelitian (Saeni \& Arief, 2016) yang dilakukan di Daerah Pesisir Desa Tadui Kecamatan Mamuju pada 91 anak sekolah yang menjadi sampel, juga menunjukkan bahwa ada hubungan kebiasaan mencuci tangan setelah BAB dengan kejadian kecacingan. Pada kebiasaan mencuci tangan setelah $\mathrm{BAB}$, siswa yang memiliki kebiasaan tidak mencuci tangan ada 23 siswa yang dinyatakan positif terinfeksi cacing, sedangkan pada siswa yang memiliki kebiasaan mencuci tangan ada 44 siswa yang dinyatakan positif terinfeksi cacing. Pada penelitian ini kita dapat melihat bahwa meski anak memiliki kebiasaan mencuci tangan setelah BAB juga masih berpotensi mengalami kecacingan itu disebabkan karena ada faktor lain yang menyebabkan seorang anak mengalami kecacingan seperti kebiasaan mandi dan kebersihan kuku pada anak.

Pada penelitian (Tifannov, 2018) yang dilakukan di SD Islam Taqwiyatul Wathon, Kelurahan Tanjung Mas, Semarang Utara pada 
Jurnal Sulolipu : Media Komunikasi Sivitas Akademika dan Masyarakat

Vol. 20 No.22020

e-issn : 2622-6960, p-issn : 0854-624X

92 siswa yang menjadi sampel. Penelitian ini bertujuan untuk mengetahui hubungan pencemaran angka kejadian infeksi cacing usus Soil Transmintted Helminths dengan kebiasaan mencuci tangan siswa di Sd Islam Taqwiyatul Wathon. Desain penelitiannya adalah cross sectional. Hasil yang ditemukan adalah adanya hubungan kebiasaan mencuci tangan siswa dengan kejadian infeksi cacing usus Soil Transmintted Helminths. Pada penelitian ini dinyatakan positif terinfeksi cacing sebanyak 7 siswa. Adapun siswa yang masuk dalam kategori memiliki kebiasaan buruk dalam cuci tangan ada 5 siswa yang dinyatakan positif terinfeksi cacing, sedangkan untuk yang miliki kebiasaan cuci tangan yang baik ada 2 siswa yang dinyatakan positif terinfeksi cacing. Adapun siswa yang memiliki kebiasaan buruk dalam mencuci tangan berpotensi lebih besar terinfeksi cacing daripada siswa yang memiliki kebiasaan baik dalam mencuci tangan.

Adapun faktor yang bisa menyebabkan siswa terinfeksi kecacingan berdasarkan observasi yang dilakukan peneliti yaitu siswanya kurang mengenal tentang Perilaku Hidup Bersih dan Sehat (PHBS). Kebanyakan siswanya berkuku panjang dan tidak terawat sehingga memiliki risiko penularan terinfeksi telur cacing STH karena penularannya dapat dari tangan ke mulut, serta kebiasaannya yang tidak membiasakan mencuci tangan dahulu sebelum mereka mengkonsumsi makanan jajanan karena telur cacing STH dapat masuk ke dalam perut melalui jari-jari tangan mereka yang dimasukkan ke dalam mulut.

Pada penelitian (Dewi N, 2017) yang dilakukan di Sekolah Dasar Negeri No. 5 Delod Peken Tabanan pada 105 yang menjadi sampel. Penelitian ini bertujuan untuk mengetahui hubungan antara perilaku higienitas diri dan sanitasi sekolah dengan kejadian infeksi soil transmitted helminths di Sekolah Dasar No. 5 Delod Peken Tabanan. Desain penelitiannya adalah cross sectional. Adapun salah satu penyebab siswa mengalami infeksi soil transmitted helminths di Sekolah Dasar No. 5 Delod Peken Tabanan ialah aktifitas mencuci tangan. Pada penelitian ini dinyatakan sebanyak 8 siswa yang positif terinfeksi cacing. Adapun yang memiliki kebiasaan cuci tangan yang buruk ada 7 anak dinyatakan positif terinfeksi cacing, sedangkan yang memiliki kebiasaan mencuci tangan dengan baik ada 1 anak dinyatakan positif terinfeksi cacing. Adapun siswa yang memiliki kebiasaan buruk dalam mencuci tangan berpotensi lebih besar terinfeksi cacing daripada siswa yang memiliki kebiasaan baik dalam mencuci tangan.

Pada penelitian (Kartini, 2016) yang dilakukan di Sekolah Dasar Negeri Kecamatan Rumbai Pesisir Pekanbaru pada 240 siswa yang menjadi sampel. Penelitian ini bertujuan untuk mengetahui proporsi dan faktor-faktor yang berhubungan dengan kejadian kecacingan Soil Transmitted Helminth (STH). Desain penelitiannya adalah cross sectional. Adapun hasil penelitian yang ditemukan oleh peneliti yaitu adanya hubungan kebiasaan mencuci tangan pakai sabun dengan kejadian infeksi kecacingan dengan nilai pvalue $=0,001$. Pada penelitian ini total siswa yang terinfeksi cacing sebanyak 39 siswa. Siswa yang memiliki kebiasaan tidak cuci tangan ada sebanyak 30 siswa dinyatakan mengalami infeksi cacing dan untuk siswa yang memiliki kebiasaan cuci tangan ada 9 siswa mengalami infeksi cacing. Adapun siswa yang memiliki kebiasaan tidak cuci tangan berpotensi lebih besar terinfeksi cacing daripada siswa yang memiliki kebiasaan cuci tangan. Siswa selama beraktifitas seperti bermain dan buang air besar anak bisa menyentuh tinjanya atau tanah yang mengandung telur cacing sehingga tangan mereka dapat menularkan cacing apabila tidak dicuci setelah buang air besar, setelah bermain serta sebelum makan karena telur cacing dapat tertelan melalui tangan tersebut

Pada penelitian (Syahrir \& Aswadi, 2016) yang dilakukan di SDN Inpres No. 1 Wora Kecamatan Wera Kabupaten Bima pada 91 siswa yang menjadi sampel. Penelitian ini bertujuan untuk mengetahui Faktor-faktor yang berhubungan Dengan Kejadian Kecacingan Pada Siswa SDN Inpres 1 Wora Kecamatan Wera Kabupaten Bima. Desain penelitiannya adalah cross sectional. Adapun hasil penelitian yang ditemukan oleh peneliti yaitu adanya hubungan bermakna antara kebiasaan mencuci tangan dengan kejadian kecacingan pada siswa dengan nilai $P=0,00$. Pada penelitian ini total siswa yang terinfeksi cacing yaitu sebanyak 54 siswa. Siswa yang memiliki kebiasaan cuci tangan yang tidak baik ada sebanyak 51 siswa yang terinfeksi cacing dan untuk siswa yang memiliki kebiasaan cuci tangan ada 3 siswa mengalami infeksi cacing. 
Jurnal Sulolipu : Media Komunikasi Sivitas Akademika dan Masyarakat

Vol. 20 No.22020

e-issn : 2622-6960, p-issn : 0854-624X

Seseorang dengan kebiasaan mencuci tangan yang tidak baik menyebabkan kecacingan yang sering dipengaruhi oleh perilaku anak yang tidak baik seperti tidak mencuci tangan setelah buang air besar, tidak mencuci kaki dan tangan dengan sabun setelah bermain di tanah, atau makan sambil bermain dengan tanah. Adapun salah satu waktu penting perlunya cuci tangan pakai sabun yang dinyatakan dalam Permenkes ialah sesudah buang air besar/kecil (Republik Indonesia, 2014).

Perbedaan angka infeksi kecacingan pada masing-masing hasil penelitian diatas kemungkinan disebabkan oleh berbagai faktor seperti kondisi sanitasi lingkungan ataupun kebersihan diri perseorangan. Adapun upaya penanggulangan kecacingan ialah dengan meningkatkan pengetahuan masyarakat tentang tanda dan gejala cacingan serta cara penularan dan pencegahannya, meningkatkan perilaku hidup bersih dan sehat, meningkatkan perilaku mengkonsumsi obat cacing terutama bagi anak balita dan anak sekolah dan meningkatkan kordinasi institusi dan lembaga serta sumber daya untuk terselenggaranya reduksi cacingan (Republik Indonesia, 2017).

\section{Hubungan Cuci Tangan Pakai Sabun Sesudah Bermain Dengan Kejadian Infeksi Kecacingan}

Infeksi yang terjadi pada siswa kemungkinan juga berasal dari aktifitas bermain yang melakukan kontak dengan tanah di luar lingkungan sekolah ataupun rumah yang tidak diimbangi dengan mencuci tangan pakai sabun setelah bermain. Pada penelitian (Putra, 2019) yang dilakukan di SD Daerah Pesisir Desa Tadui Kecamatan Mamuju tahun 2019 pada 33 orang anak yang menjadi sampel penelitian yang menjadi penjadi penyebab ialah aktifitas anak setelah bermain tidak mencuci tangan. Penularan lazimnya terjadi melalui mulu atau luka di kulit (cacing tambang) oleh telur atau larva cacing yang bisa terdapat dimana-mana, misalnya di tanah, debu dan lantai (Tan \& Rahardja, 2010).

Pada penelitian (Syahrir \& Aswadi, 2016) yang dilakukan di SDN Inpres No. 1 Wora Kecamatan Wera Kabupaten Bima pada 91 siswa yang menjadi sampel juga siswa mengalami infeksi kecacingan salah satunya dipengaruhi oleh faktor kebiasaan anak mencuci tangan setelah bermain. Pada penelitian (Kartini, 2016) yang dilakukan di
Sekolah Dasar Negeri Kecamatan Rumbai Pesisir Pekanbaru pada 240 siswa yang menjadi sampel juga kejadian infeksi kecacingan dipengaruhi oleh kebiasaan anak mencuci tangan. Apabila seorang penderita cacingan membuang tinja diatas tanah maka telur-telur cacing akan menyebar kemana-mana sampai ke tempat anak-anak bermain (Sutomo, 1995).

Cacing apabila telah dewasa akan menimbulkan penyakit dan gangguan kesehatan seperti menurunnya kondisi kesehatan, gizi, kecerdasan dan produktivitas penderita sehingga secara ekonomi banyak menyebabkan kerugian, karena adanya kehilangan karbohidrat dan protein serta kehilangan darah yang pada akhirnya dapat menurunkan kualitas sumber daya manusia. Adapun salah satu sifat cacing ialah patogenitas, dimana pada umumnya peranan cacing yang telah dewasa pada tubuh manusia dengan jalan seperti menghisap darah tuan rumah, menghisap darah dan mengeluarkan bisa (racun), dan di dalam tubuh (usus) menghisap zat-zat makanan tuan rumah (manusia) hingga kekurangan zat makanan (Adam, 1995).

Adapun jenis- jenis cacing yang menginfeksi anak-anak sekolah dasar yang paling sering ditemui pada penelitian diatas ialah cacing Ascharis lumbricoides (cacing gelang), cacing Trichuris trichiura (cacing cambuk), cacing tambang dan cacing Enterobius vermicularis (cacing kremi). Infeksi dengan cacing kremi paling banyak terjadi, biasanya sewaktu anak-anak bermain ditanah, dimana telur-telur cacing melekat pada kuku dan jari tangan, adapun telur-telur cacing gelang yang dikeluarkan dengan tinja dapat menulari, terutama anak-anak bila bermain ditanah (Tan \& Rahardja, 2010). Cara yang paling baik dalam memutus rantai penularan infeksi kecacingan yang ditularkan melalui tanah, antara lain dengan menjaga kebersihan diri misalnya mencuci tangan dengan sabun selesai bermain dan menggunting kuku secara rutin. 
Jurnal Sulolipu : Media Komunikasi Sivitas Akademika dan Masyarakat

Vol. 20 No.22020

e-issn : 2622-6960, p-issn : 0854-624X

\section{KESIMPULAN}

Berdasarkan hasil dan pembahasan penelitian diatas dapat disimpulkan bahwa:

a. Ada hubungan kebiasaan mencuci tangan pakai sabun sebelum makan dengan kejadian infeksi kecacingan pada anak sekolah dasar.

b. Ada hubungan kebiasaan cuci tangan pakai sabun sesudah buang air besar (BAB) dengan kejadian infeksi kecacingan pada anak sekolah dasar.

c. Ada hubungan kebiasaan cuci tangan pakai sabun sesudah bermain dengan kejadian infeksi kecacingan pada anak

\section{SARAN} sekolah dasar.

a. Sebaiknya para orang tua ataupun guru di sekolah mengajarkan dan menerapkan kepada anak-anak untuk selalu mencuci tangan pakai sabun setelah beraktiftas seperti mencuci tangan pakai sebelum makan, sesudah $B A B$ dan setelah bermain untuk dapat mencegah anak terinfeksi kecacingan ataupun penyakit lain.

b. Sebaiknya setiap sekolah mengadakan sarana tempat cuci tangan dan menyediakan sabun sehingga anak-anak bisa mencuci tangan setelah bermain ataupun sebelum makan dengan benar.

c. Sebaiknya mahasiswa ataupun pihak puskesmas untuk melakukan sosialisasi kepada anak-anak akan pentingnya perilaku hidup bersih dan sehat seperti mencuci tangan pakai sabun untuk mencegah penularan suatu penyakit. Dan pihak puskesmas selalu mengaktifkan pemberian obat cacing kepada anak setiap 6 bulan sekali.

\section{DAFTAR PUSTAKA}

Adam, S. (1995). Dasar-dasar Mikrobiologi Parasitologi Untuk Perawat (2nd ed.; S. E. Linda, Ed.). Jakarta: EGC.

Atmojo, A. T. (2019). Trichuris trichiura (Cacing Cambuk). Retrieved from Indonesian Medical Laboratory. (Online) website: https://medlab.id/trichuris-trichiura/ diakses pada 8 Januari 2020

Biologigonz.blogspot.com. (2015). Cacing Ascaris - Cacing Perut. Retrieved from Biologi Gonzaga. (Online) website: https://biologigonz.blogspot.com/2015/03/cacing-ascaris-cacing-perut.html diakses 8 Januari 2020

Chadijah, S., Sumolang, P. P. F., \& Veridiana, N. N. (2014). Hubungan Pengetahuan, Perilaku, Dan Sanitasi Lingkungan Dengan Angka Kecacingan Pada Anak Sekolah Dasar Di Kota Palu. Media Penelitian Dan Pengembangan Kesehatan, 24(1), 50-56. (Online) https://doi.org/10.22435/mpk.v24i1.3487.50-56 diakses 21 Desember 2019

Dewi N, L. D. dan D.A.A.S Laksmi (2017). Hubungan perilaku higienitas diri dan sanitasi sekolah dengan infeksi Soil-transmitted helminths pada siswa kelas III-VI Sekolah Dasar Negeri No. 5 Delod Peken Tabanan Tahun 2014. (Online) E-Jurnal Medika, 6(5), 1-4. Diakses 16 April 2020

Dinkes Kota Makassar. (2019). Profil Kesehatan Kota Makassar Tahun 2019. Makassar. Dinas Kesehatan Kota Makassar.

Fafunwa, T. S., Mogaji, H. O., Oluwole, A. S., Adeniran, A. A., Fagbenro, M. T., Sam-Wobo, S. O., ... Ekpo, U. F. (2017). Water Resource, Hygienic Practice, and Soil Transmitted Helminthiasis in Some Rural Communities of Osun State, Nigeria. Journal of Water Resource and Protection, 09(02), 99-110. (Online) https://doi.org/10.4236/jwarp.2017.92008 diakses 22 Desember 2019

Hanif, Yunus, \& Gayatri. (2017). Gambaran Pengetahuan Penyakit Cacingan. Jurnal Preventia, 211. (Online) https://doi.org/10.1016/0006-8993(94)91579-2 diakses 22 Desember 2019

Ideham, B., \& Pusarawati, S. (2007). Pendahuluan. In Helmintologi Kedokteran. Surabaya: 
Jurnal Sulolipu : Media Komunikasi Sivitas Akademika dan Masyarakat

Vol. 20 No.22020

e-issn : 2622-6960, p-issn : 0854-624X

Airlangga University Press.

Johan Ade Wicaksono, C., Suswaty, S., Heru Apriantoro, N., \& Sasongko, A. (2018). Prevalensi Infeksi Cacing Usus Pada Anak Di Kampung Pasar Keputran Utara, Surabaya Tahun 2017. Journal of Vocational Health Studies. Elseveir, 01(01), 97-101. (Online) https://ejournal.unair.ac.id/JVHS/article/download/9693/5415 diakses 21 Desember 2019

Kartini, S. (2016). Kejadian kecacingan pada siswa sekolah dasar negeri kecamatan rumbai pesisir pekanbaru the helminthiasis on the state elementary school dtudent on kecamatan Rumbai Pesisir Pekanbaru. Jurnal Kesehatan Komunitas, 3(2), 53-58. (Online) https://doi.org/10.25311/jkk.Vol3.Iss2.102 diakses 20 Desember 2019

Magee, R. V., س.علامة, Magee, R. V., Crowder, R., Winters, D. E., Beerbower, E., ... Gorski, P. C.

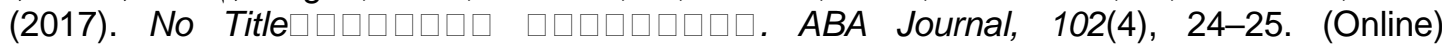
https://doi.org/10.1002/ejsp.2570 diakses 20 Desember 2019

Muchlas, F. (2010). Cacing Tambang. Retrieved from Markas Jur. Biologi (Online)website:https://crocodilusdaratensis.wordpress.com/2010/08/17/cacing-tambang/ diakses 8 Januari 2020

Munir, M. A., White, I. P. F. I., \& Ramadani, A. S. (2019). Identifikasi Telur Cacing Pada Spesimen Feses Anak-Anak Di Panti Asuhan Raudhatul Ummat Palu. (Online) http://jurnal.untad.ac.id/jurnal/index.php/HealthyTadulako/article/view/12625 diakses 20 Desember 2019

Natadisastra, D., \& Agoes, R. (2009). Parasitologi Umum. In N. Z. Astuti (Ed.), Parasitologi Kedokteran Ditinjau Dari Organ Tubuh Yang Diserang (1st ed., pp. 5-14). Jakarta: EGC.

Notoatmodjo, S. (2018). Metodologi Penelitian Kesehatan (3rd ed.). Jakarta: PT Rineka Cipta.

Pitriani, \& Herawanto. (2019). Host (penjamu), Agent, Lingkungan. In F. A. Gobel (Ed.), Epidemiologi Kesehatan Lingkungan (1st ed., pp. 56-68). Makassar: Nas Media Pustaka.

Putra, R. N. (2019). Hubungan Kebiasaan Mencuci Tangan Sebelum Makan Dengan Kejadian Infeksi Cacing Pada Anak SDN Dukuh Kupang V Surabaya. Hubungan Kebiasaan Mencuci Tangan Sebelum Makan Dengan Kejadian Infeksi Cacing Pada Anak SDN Dukuh Kupang V Surabaya, 1-75. Retrieved from (Online) http://erepository.uwks.ac.id/6238/1/format.pdf diakses 16 April 2020

Ramayanti, I. (2018). Prevalensi Infeksi Soil Transmitted Helminths pada Siswa Madrasah Ibtidaiyah Ittihadiyah Kecamatan Gandus Kota Palembang. (Online) http://jurnal.umpalembang.ac.id/syifamedika/article/view/1352 diakses 20 Desember 2019

Republik Indonesia, P. (2014). Peraturan Menteri Kesehatan Republik Indonesia Nomor 3 Tahun 2014 Tentang Sanitasi Total Berbasis Masyarakat.

Republik Indonesia, P. (2017). Peraturan Menteri Kesehatan Republik Indonesia Nomor 15 Tahun 2017 Tentang Penanggulangan Cacingan.

Riansnop@gmail.com. (2017). Cacing Tambang (Necator americanus dan Ancylostoma duodenale). Retrieved from Blogspot.com (Online) website: http://laboratoriumanaliskesehatan.blogspot.com/2017/01/ cacing-tambang-necatoramericanus-dan.html diakses 8 Januari 2019

Ryadi, A. L. S. (2016). Ilmu Kesehatan Masyarakat (A. A. C, Ed.). Yogyakarta: Gramedia.

Saeni, R. H., \& Arief, E. (2016). Kebiasaan Mencuci Tangan Pada Anak Sekolah Dengan Kejadian 
Jurnal Sulolipu : Media Komunikasi Sivitas Akademika dan Masyarakat

Vol. 20 No.22020

e-issn : 2622-6960, p-issn : 0854-624X

Kecacingan Di Daerah Pesisir Desa Tadui Kecamatan Mamuju. Jurnal Kesehatan Manarang, 3, 1-6. Retrieved from (Online) http://jurnal.poltekkes mamuju.ac.id/index.php/m/article/download/33/33/ diakses 16 April 2020

Setyawan, F. E. B. (2019). Pendekatan Pelayanan Kesehatan Dokter Keluarga (pendekatan Holistik Komprehensif (1st ed.; Emjy, Ed.). Malang: FK UMM.

Sutomo, A. H. (1995). Kader Kesehatan Masyarakat (II; Y. Asih, ed.). Jakarta: Buku Kedokteran EGC.

Syahrir, S., \& Aswadi. (2016). Faktor yang berhubungan Dengan kejadian kecacingan pada siswa SDN Inpres no. 1 wora kecamatan wera Kabupaten Bima. J.Kesehatan Masyarakat, 2(1), 4148. (Online) http://journal.uin-alauddin.ac.id/index.php/higiene/article/view/1805 diakses 21 Desember 2019

Tan, T., \& Rahardja, K. (2010). Obat-Obat Sederhana untuk Gangguan Sehari-hari. Jakarta: PT Alex Media Komputindo.

Tifannov, A. L. (2018). Infeksi Cacing Usus Soil Transmitted Helminths Terhadap Kebiasaan Mencuci Tangan pada Siswa SD. Jaringan Laboratorium Medis, 1-5. Retrieved from (Online) http://ejournal.poltekkessmg.ac.id/ ojs/index.php/JLM/article/view/4922 diakses April 2020

Triwijanarko, Ramadhan. 2017. Ternyata 75\% Orang Indonesia Tak Cuci Tangan dengan Sabun. (Online)

https://www.marketeers.com/mencuci-tangan-dengansabun/\#: :text=Menurut\%20data\%20WHO\%20(2014)\%2C,saluran\%20pernapasan\%20akut \%2C\%20termasuk\%20pneumonia.\&text=Kegiatan\%20ini\%20merupakan\%20salah\%20satu, menyasar\%20anak\%2Danak\%20usia\%20dini. (diakses Desember 2020)

Wahyudi, S. T. (2017). Statistika Ekonomi Konsep, Teori dan Penerapannya (1st ed.). Malang: Tim UB Press.

Zulkoni, A. (2011). Parasitologi. Yogyakarta: Nuha Medika. 